\title{
MPV Regimen
}

National Cancer Institute

\section{Source}

National Cancer Institute. MPV Regimen. NCI Thesaurus. Code C140108.

A regimen consisting of methotrexate, procarbazine and vincristine that can be used in the treatment of central nervous system (CNS) lymphoma. 